Giovanni Bella / Carla Massidda

\title{
The Trade-Off Between Tourism and Pollution for Japanese Economic Growth
}

\section{Abstract}

This paper proposes a vector error correction model to investigate the relationship between polluting emissions and GDP levels in Japan, in the period 1970-2014, and tests the validity of the Environmental Kuznets Curve (EKC) hypothesis driven by tourist arrivals. Our results validate the existence of two different causality channels among the selected variables. In particular, we find that a trade-off might exist between increasing the number of tourists, which drives economic growth, and the pattern of a sustainable development, due to the increase of polluting emissions. The analysis allows us to propose appropriate policy strategies to promote a robust and sustainable long run economic growth.

Keywords: environmental Kuznets curve, tourism pollution, VECM analysis, long run causality, Japan

\section{Introduction}

Japanese tourism has climbed in recent years several positions in the international tourism ranking as the fastest-growing travel destination. In particular, after six straight years of double-digit growth, in 2017 it joined the group of the top ten for receipts. In terms of arrivals, it reached the 12th position of the world tourism destinations, and, according to the World Tourism Organization (UNWTO, 2008), the country is therefore expected to seize a prominent position atop the rank very soon.

Given these characteristics, the absolute impact of tourism on the Japanese economy is noteworthy. In particular, in 2017 the tourism economy produced 6.8\% of total GDP (331.2bn USD), 6.4\% of total employment $(4,171,500$ jobs), and $4.1 \%$ of total exports (35.3bn USD). Although these effects are significant, the Japanese tourism economy is still far from having exploited all its potential. Yet, looking at tourism contribution in relative terms, Japan ranks only 136th and 129th for GDP and employment, respectively, after China and Northeast on average. It ranks 142nd for export.

Besides the increasing affordability of international flights and the rise of China's outflows, other important internal factors are driving the recent expansion of Japanese inbound tourism (Andonian et al., 2016). Among them, the policy of relaxing visa restrictions, together with the depreciation of the Yen on the currency markets, has played a significant role. All these matters have aimed to support the decision taken by Japan's leaders to become a 'tourism-oriented country' and to use tourism as the primary tool to solve social and economic challenges. The aspirational target to raise annual inbound tourism to 40 million in 2020, the year of the Olympic Games in Japan, is a clear example of how Japan's tourism industry is on the verge of becoming a major engine for economic growth.

This decision finds its theoretical and empirical support in the so-called tourism-led growth hypothesis (TLGH), which is nowadays the most common approach to describe the link between tourism and growth (cf., inter al, Aliyev \& Ahmadova, 2020; Gwenhure \& Odhiambo, 2017; Balaguer \& Cantavella-Jorda, 2002; Katircioglu,

Giovanni Bella, PhD, Corresponding author, Department of Economics and Business, University of Cagliari, Cagliari, Italy; ORCID ID: https://orcid.org/0000-0001-5033-1711; e-mail: bella@unica.it

Carla Massidda, PhD, Department of Economics and Business, University of Cagliari, Cagliari, Italy;

ORCID ID: https://orcid.org/0000-0003-3295-8240; e-mail: massidda@unica.it

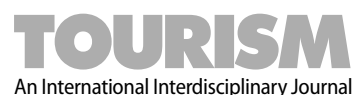


2009, 2010). Accordingly, tourism is expected to drive economic growth along with several mechanisms: it increases foreign exchange earnings, enhances the overall efficiency of the economic system, by increasing the competition among firms, and it helps the country to exploit economies of scale.

However, the decision to become a 'tourism-oriented country,' besides the expected positive economic results, might also be a harbinger of negative consequences. An example of the rising concerns on this issue is wellcaptured by the neologism 'tourism pollution' (kankō kōgai) used to define the way new inbound tourism flows is harming the quality of life in Japan. Rapid growth with the highly skewed regional distribution of tourists also means environmental and social pressure, stressed infrastructure, overcrowded major attractions, and capacity constraints in major cities. Lastly, and somehow more importantly, mass tourism development is expected to boost pollution associated with the level of carbon dioxide emissions $\left(\mathrm{CO}_{2}\right)$.

As it is well known, tourism activity is considered an active contributor to $\mathrm{CO}_{2}$ emissions along with both a direct and an indirect channel. A direct channel runs from tourism development to the increase in energy use due to expansion of all tourism-related economic activities, such as transportation, catering, accommodation, water supply, and the management of tourist attractions (cf. inter al., Gössling, 2000; Gössling et al., 2005). Conversely, the indirect channel depends on the role that tourism has in leading economic growth, according to the TLGH introduced above, since tourism contributes to rising $\mathrm{CO}_{2}$ as long as it drives the growth process. In this regard, however, caution is needed because the sign of the relationship between economic growth and $\mathrm{CO}_{2}$ is controversial. Mass tourism activities can degrade the environment through the high use of energy and transportations. However, the promotion of environmentally friendly tourist programs can help growth and therefore easily contribute to natural resource conservation.

A recent bulk of empirical research aims to exploit the impact of tourism on $\mathrm{CO}_{2}$ emissions by revisiting the well-known Environmental Kuznets Curve (EKC) hypothesis with the additional the channel of tourism development (Katircioglu, 2014a, 2014b; De Vita et al., 2015; Ozturk et al., 2015; Arbulù et al., 2015; Zaman et al., 2016, Paramati et al., 2017; Bella, 2018).

In particular, after Grossman and Krueger (1995), a huge bulk of literature has investigated the inverted U-shaped relationship implied by the EKC hypothesis for different indicators of environmental degradation (Copeland \& Taylor, 2004; Dinda 2004). According to this field of analysis, the EKC curve postulates that initial growth can deteriorate the environment until it reaches a turning point, after which environmental quality improves (cf. Stern, 2004, for a comprehensive review). The standard EKC model has usually considered GDP as the only explanatory variable. However, the use of a simple bivariate framework may lead to misleading and inconclusive results. Therefore, a strand of literature has extended the standard relationship by adding other variables such as energy use and electric power consumption (Stern, 2004; Apergis \& Payne, 2009; Lean \& Smith, 2010) as possible covariates necessary to explain the relationship between polluting emissions and per capita income. Given the above considerations, this paper aims to contribute to the literature by providing an empirical investigation of the relationship between tourism flows and pollution in a multivariate context to control for the main determinants of $\mathrm{CO}_{2}$ emissions in Japan. In particular, our approach estimates a relationship of the following form

$$
y_{t}=\beta_{0}+\sum_{j=1}^{k} \beta_{j} x_{j t}
$$

where $y$ represents pollution, and $x$ is a set of explanatory variables. As detailed in Table 1 , we consider the levels of $\mathrm{CO}_{2}$ as a proxy of polluting emissions, whereas the level and squared values of GDP, the number of tourist arrivals, and the amount of both energy use and fossil fuels used in the production process are taken as possible independent covariates. 
Table 1

Variables of the model

\begin{tabular}{l|c|l}
\hline Indicator name & Variable & \multicolumn{1}{|c}{ Measurement } \\
\hline $\mathrm{CO}_{2}$ emissions & $c$ & Metric tons per capita \\
GDP per capita & $y$ & Constant 2010 US\$ \\
Squared GDP per capita & $y^{2}$ & Constant 2010 US\$ \\
Energy use & $e$ & Kg of oil equivalent per capita \\
Tourist arrivals & $a$ & International inbound tourists \\
Fossil fuels & $f$ & Percentage of fossil fuels on total energy consumption \\
\hline
\end{tabular}

For the scope of our analysis, and in line with Stern (2004) and Katircioglu et al. (2014), we study the following explicit regression model:

$$
c=\beta_{0}+\beta_{1} y+\beta_{2} y^{2}+\beta_{3} e+\beta_{4} a+\beta_{5} f+\varepsilon_{t}
$$

Since all variables are expressed in natural logarithms, the estimated parameters $\left(\beta_{0}, \beta_{1}, \beta_{2}, \beta_{3}, \beta_{4}, \beta_{5}\right)$ result in terms of elasticities. Moreover, $\varepsilon_{t}$ is the error term. The Bonferroni test for nonlinearity was conducted. The test provided a $\chi^{2}$ statistic of $47.38^{* * *}(0.000)$, with p-values reported in brackets. Since both methods test the null of absence of nonlinear dependence, we can conclude that a nonlinear relationship exists between the variables in the model (Brida et al., 2015; Po \& Huang, 2008).

Table 2

Summary of descriptive statistics, 1970-2014

\begin{tabular}{c|r|r|r|r|r}
\hline Variable & \multicolumn{1}{c|}{ Mean } & \multicolumn{1}{c|}{ Median } & \multicolumn{1}{c|}{ S.D. } & Minimum & Maximum \\
\hline$c$ & 9.130429 & 9.317427 & 0.829186 & 7.362587 & 10.26173 \\
$y$ & $32,240.15$ & $34,628.62$ & $8,836.33$ & $17,345.01$ & $46,466.12$ \\
$y^{2}$ & $1.12 \mathrm{e}+09$ & $1.20 \mathrm{e}+09$ & $5.71 \mathrm{e}+08$ & $3.01 \mathrm{e}+08$ & $2.16 \mathrm{e}+09$ \\
$e$ & $3,427.899$ & $3,551.162$ & 513.8064 & $2,458.357$ & $4,083.832$ \\
$a$ & $3,933,437.0$ & $3,410,447.0$ & $2,966,311.0$ & $660,715.0$ & $1.34 \mathrm{e}+07$ \\
$f$ & 87.11275 & 84.57581 & 5.959052 & 79.40919 & 97.3456 \\
\hline
\end{tabular}

In our analysis, the variables in (2) are specified by using annual data for Japan obtained from the World Development Indicators database (World Bank, 2016) over the period 1970-2014. In addition, Table 2 displays the summary of descriptive statistics. In particular, notice that the mean value of per capita $\mathrm{CO}_{2}$ emissions is around 9.13 metric tons; the mean number of tourist arrivals is close to four million units, and the per capita GDP of our dataset ranges from $17,345 \$$ to $46,466 \$$.

The evolutionary pattern of the variables in the specified model is shown in Figure 1. In particular, we may notice that both GDP and tourism arrivals trajectories follow an increasing trend. In contrast, data on $\mathrm{CO}_{2}$ emissions and energy use are more characterized by an oscillating pattern. It is interesting to observe that in 2011, the year of the Fukushima nuclear disaster, a breakpoint in the data is observed. Data show that from that point, the decision to shut nuclear plants down has magnified the downwards shift on the amount of energy used. This occurred jointly with a shift in industry energy sources that sharply moved back to the use of standard fossil fuels and inevitably pushed polluting emissions to rise. Notwithstanding, from the same point in time, Japan experienced a pronounced upswing in tourism flows, reaching levels never experienced hitherto. 
Figure 1

Variables evolutionary pattern, 1970-2014
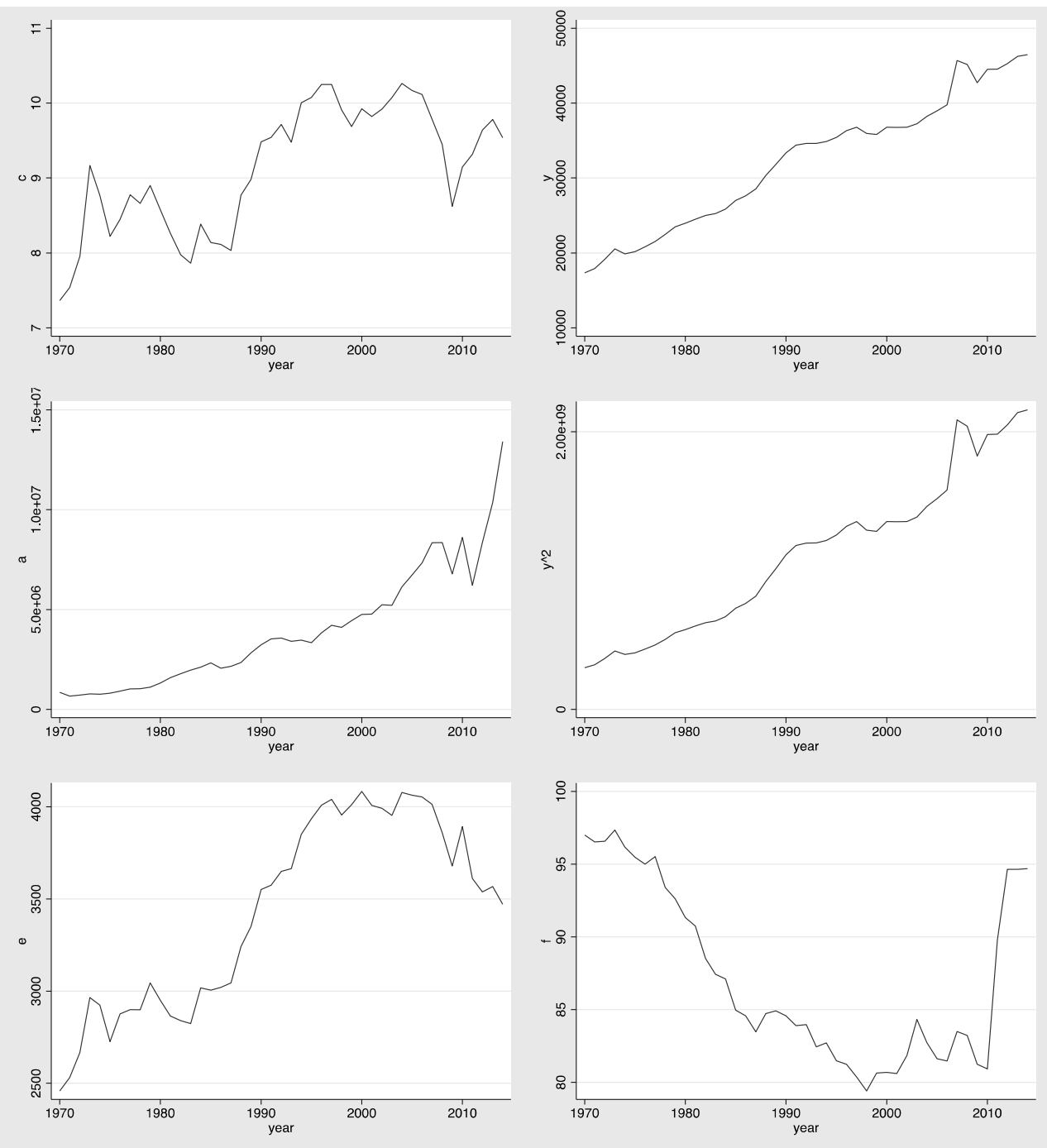

\section{The drivers of $\mathrm{CO}_{2}$ emissions in Japan: The role of tourism}

In Japan, the decision to become a 'tourism-oriented country' is aimed at boosting economic growth and rising national wellbeing. Although this policy is set up according to reasonable targets, the risk that a sharp acceleration of tourism development will worsen the environmental quality is very high. $\mathrm{CO}_{2}$ emissions generated by tourism activities are one of the possible threats. This is a reasonable fear given that, of about 35 gigatons of $\mathrm{CO}_{2}$ emitted worldwide, $5 \%$ is generated by the tourism sector. Of these, $75 \%$ can be attributed to transportation ( $40 \%$ by air and $30 \%$ by car), whereas $21 \%$ to accommodation, and $4 \%$ to tourist activities (cf. UNWTO, 2008).

Japanese $\mathrm{CO}_{2}$ emissions amount to 1,325 million tons (3.7\% worldwide), mainly given by industry, transport, and commerce activities. GDP and energy-originated $\mathrm{CO}_{2}$ emissions display similar upward trends until 2013. Only after, we assist in decoupling between growth and pollution, with growth persistently rising and $\mathrm{CO}_{2}$ slightly decreasing. This trend responds to the increasing attention that Japanese leaders place on 
the preservation of the environmental quality. For this reason, understanding the weight of tourism among the different drivers of $\mathrm{CO}_{2}$ emissions turns out as a crucial issue for the implementation of future effective conservation policies.

With the above considerations, our study aims to find evidence of a causality nexus giving simultaneously rise to the three different scenarios proposed by the literature, and prove that: $i$ ) tourism arrivals positively contribute to national GDP (the tourism-led growth hypothesis, TLGH); ii) an increase in tourism flows negatively affects environmental quality by increasing polluting emissions (the tourism-led pollution hypothesis, TLPH); iii) pollution loads are linked to economic growth in an inverted-U pattern, meaning that pollution is expected to lower in the long run as GDP grows (the EKC hypothesis). The next section is devoted to this scope. Finally, the forecast analysis of a prevailing channel among the different hypothesis tested will be discussed in the concluding section.

\section{Research strategy}

\subsection{Theoretical setting}

With respect to the standard specification (where $\beta_{3}=\beta_{4}=\beta_{5}=0$ ), the theoretical setting in model (2), with $\beta_{3,4,5} \neq 0$, has the advantage of taking the standard EKC-related analysis a step further. In particular, the introduction of the tourism variable helps to overcome potential omitted variables bias and to capture the impact of tourism flows on both income production and pollution loads. For example, Adamou and Clerides (2010) and Castro Nuño et al. (2013), show the existence of a possible threshold at which tourism starts to negatively impact economic growth, or at the most, its effects become uncertain. Both analyses assume per capita level of GDP as the dependent variable, whereas tourism and pollution are the explanatory variables of the model. However, this setting may revert the causality link implied by the standard EKC hypothesis, where pollution reduction is determined by sustained economic growth, possibly driven by the tourism sector. Additionally, the panel analyses shown in these studies may overlook the economic structure of each individual country and therefore drive to wrong policy conclusions.

Mathematically, if $\beta_{1}>0$ and $\beta_{2}<0$, a quadratic, bell-shaped, relationship exists, where the exponential $e^{-\beta 1 / \beta 2}$ provides the value of GDP at which the curve reaches its maximum, that is referred to in the literature as the turning point value above which pollution starts declining (Stern, 2004).

To estimate the parameters of the model in (2), the literature has proposed several techniques that include the standard OLS analysis, or slightly more sophisticated time-series approaches, which allow investigating for the presence of cointegrating relationships amongst the variables. The latter is preferable for the multivariate framework of our analysis. Indeed, the driver of pushing output growth as a force to lower emission loads could be overwhelmed by other sources of causation. It is therefore of interest to ascertain the correct direction of causality linking emissions to the various dependent variables, both in the short and long run, and consequently infer the appropriate policy interventions that can effectively drive the economy onto a sustainable economic growth path.

\subsection{The VECM methodology}

The present section is meant to investigate the causality nexus among the variables used in the stochastic decomposition analysis. This allows us to analyze the projection of future emissions necessary to conclude in terms of appropriate implications for climate policy actions: whether for example it is better to intervene on the scale effects (pushing up economic growth and the number of tourists), or on the counteracting technology effects (such as improving energy efficiency improvement and decreasing the industry dependence on fossil fuels). 
To derive the associated speed of adjustment between the short and long run estimates of the dependent variable, the following error correction model is estimated:

$$
\Delta x_{t}=\hat{\alpha} \Pi x_{t-1}+\sum_{i=1}^{p-1} \Gamma_{i} \Delta x_{t-i}+\gamma+u_{t}
$$

where, $\Delta x_{t}$ is the vector of lagged variables in (2), $\Delta$ measures the change in all variables, $p$ is the number of lags, $\gamma$ is the vector of constant terms, $\Gamma_{i}$ is a matrix of the short-term coefficients, and $\Pi x_{t-1}$ is the one-period lagged error correction term $\left(E C T_{i, t-1}\right)$, which captures the disequilibrium level from the long run equilibrium values. In particular, $\Pi$ is a normalized matrix of weights, the loading matrix, measuring the average speed of convergence towards the long run equilibrium. Hence, a negative and significant $\hat{\alpha}$ coefficient indicates that any short-term fluctuations between the independent variables and the dependent variable will give rise to a stable long run relationship between the variables (Gujarati, 2003).

In our case, we need to estimate the following VEC model:

$$
\begin{aligned}
\Delta c_{t} & =\gamma_{1}+\hat{\alpha}_{1} E C T_{1, t-1}+\left(\theta_{1,1} \Delta y_{t-1}+\theta_{1,2} \Delta a_{t-1}+\theta_{1,3} \Delta e_{t-1}+\theta_{1,4} \Delta f_{t-1}\right)+u_{1, t} \\
\Delta y_{t} & =\gamma_{2}+\hat{\alpha}_{2} E C T_{2, t-1}+\left(\theta_{2,1} \Delta y_{t-1}+\theta_{2,2} \Delta a_{t-1}+\theta_{2,3} \Delta e_{t-1}+\theta_{2,4} \Delta f_{t-1}\right)+u_{2, t} \\
\Delta a_{t} & =\gamma_{3}+\hat{\alpha}_{3} E C T_{3, t-1}+\left(\theta_{3,1} \Delta y_{t-1}+\theta_{3,2} \Delta a_{t-1}+\theta_{3,3} \Delta e_{t-1}+\theta_{3,4} \Delta f_{t-1}\right)+u_{3, t} \\
\Delta e_{t} & =\gamma_{4}+\hat{\alpha}_{4} E C T_{4, t-1}+\left(\theta_{4,1} \Delta y_{t-1}+\theta_{4,2} \Delta a_{t-1}+\theta_{4,3} \Delta e_{t-1}+\theta_{4,4} \Delta f_{t-1}\right)+u_{4, t} \\
\Delta f_{t} & =\gamma_{5}+\hat{\alpha}_{5} E C T_{5, t-1}+\left(\theta_{5,1} \Delta y_{t-1}+\theta_{5,2} \Delta a_{t-1}+\theta_{5,3} \Delta e_{t-1}+\theta_{5,4} \Delta f_{t-1}\right)+u_{5, t}
\end{aligned}
$$

where:

$$
E C T_{i, t-1} \equiv \prod_{i}\left(c_{t-1} \quad y_{t-1} \quad a_{t-1} \quad e_{t-1} \quad f_{t-1}\right)^{T}
$$

with:

$$
\Pi_{i}=\left(\begin{array}{lllll}
\delta_{i, 1} & \delta_{i, 2} & \delta_{i, 3} & \delta_{i, 4} & \delta_{i, 5}
\end{array}\right)
$$

The analysis needs different steps to be accomplished. First, we need to determine if the variables of the model contain a unit root. If all variables were I(1), the presence of cointegration must be tested. Consequently, the VECM model can be estimated to infer the short and long run relationships between the variables in (2). Finally, the Granger causality test must be performed, in order to support the results of the estimates, construct a forecast scenario, and validate the underlying economic hypotheses.

\section{Results and discussion}

\subsection{Unit root testing}

Table 3 presents the unit root results based on the statistics provided by the Augmented Dickey-Fuller (ADF) test and the Phillips-Perron (PP) test, joint with the Kwiatkowski, Phillips, Schmidt, and Shin (KPSS) stationarity test. Both the ADF and the PP tests show that all series are non-stationary at all levels since the null hypothesis of a unit root cannot be rejected. However, all series become stationary at first difference, since now the null hypothesis of a unit root is rejected. Therefore, series in our dataset are integrated to the order one, i.e., I(1). This means that, when working at the first difference, any shift in time will not cause a change in the shape of the distribution. The cross-check analysis performed via the standard KPSS confirms the stationarity results obtained with the ADF and PP statistics. 
Table 3

Augmented Dickey-Fuller and Phillips-Perron unit root test results

\begin{tabular}{l|ll|ll|l}
\hline Variables & \multicolumn{2}{|c|}{ ADF test } & \multicolumn{2}{c|}{ PP test } & $\begin{array}{l}\text { KPSS test } \\
\text { statistic }\end{array}$ \\
\hline $\mathbf{c}$ & -0.358 & $(0.9169)$ & 2.429 & $(0.9900)$ & 0.228 \\
$\Delta \mathbf{c}$ & $-30.084^{* * *}$ & $(0.0000)$ & $-43.703^{* * *}$ & $(0.0000)$ & $0.0485^{* *}$ \\
$\mathbf{y}$ & -2.623 & $(0.0883)$ & -2.403 & $(0.0582)$ & 0.142 \\
$\Delta \mathbf{y}$ & $-1.780^{* *}$ & $(0.0390)$ & $-2.867^{* *}$ & $(0.0493)$ & $0.0363^{* *}$ \\
$\mathbf{y}^{2}$ & -2.400 & $(0.1418)$ & -2.298 & $(0.0995)$ & 0.169 \\
$\Delta \mathbf{y}^{2}$ & $-1.764^{* *}$ & $(0.0399)$ & $-1.339^{* *}$ & $(0.0318)$ & $0.0314^{* *}$ \\
$\mathbf{a}$ & -2.537 & $(0.1066)$ & -3.617 & $(0.1203)$ & 0.351 \\
$\Delta \mathbf{a}$ & $-13.521^{* * *}$ & $(0.0000)$ & $-48.953^{* * *}$ & $(0.0000)$ & $0.0939^{*}$ \\
$\mathbf{e}$ & -1.998 & $(0.2876)$ & -1.977 & $(0.2967)$ & 0.368 \\
$\Delta \mathbf{e}$ & $-6.275^{* * *}$ & $(0.0000)$ & $-6.290^{* * *}$ & $(0.0000)$ & $0.0132^{* *}$ \\
$\mathbf{f}$ & -1.343 & $(0.6095)$ & -1.479 & $(0.5441)$ & 0.456 \\
$\Delta \mathbf{f}$ & $-4.631^{* * *}$ & $(0.0000)$ & $-4.506^{* * *}$ & $(0.0002)$ & $0.0828^{*}$ \\
\hline
\end{tabular}

Notes: Variables in levels are labelled [L]; variables in first difference are labelled [FD].

P-values are in brackets. ${ }^{*},{ }^{* *},{ }^{* *}$ indicate significance at $10 \%, 5 \%$ and $1 \%$, respectively.

Table 4

Selection order criteria (sample: 1974-2014; number of obs: 41)

\begin{tabular}{c|c|c|c|c|c|c|c|c}
\hline Lag & LL & LR & df & p & FPE & AIC & HQIC & SBIC \\
\hline $\mathbf{0}$ & 181.754 & & & & $7.6 e-12$ & -8.57338 & -8.48207 & -8.32261 \\
$\mathbf{1}$ & 433.711 & 503.91 & 36 & 0.000 & $2.1 \mathrm{e}-16$ & -19.1079 & -18.4687 & $-17.3525^{*}$ \\
$\mathbf{2}$ & 463.509 & 59.595 & 36 & 0.008 & $3.1 \mathrm{e}-16$ & -18.8053 & -17.6182 & -15.5453 \\
$\mathbf{3}$ & 509.672 & 92.327 & 36 & 0.000 & $2.6 \mathrm{e}-16$ & -19.3011 & -17.5661 & -14.5365 \\
$\mathbf{4}$ & 582.271 & $145.2^{*}$ & 36 & 0.000 & $9.2 \mathrm{e}-17^{*}$ & $-21.0864^{*}$ & $-18.8035^{*}$ & -14.8172 \\
\hline
\end{tabular}

Next, we check the presence of cointegration among all variables. The selection of 4 lags is supported by the Akaike information criterion (AIC) in Table 4. Subsequently, the results of the Johansen $(1988,1991,1995)$ cointegration test are reported in Table 5, where the trace statistics is higher than the critical value up to rank 2. Then, the null of no cointegration can be rejected. This means that two series of our dataset seem to share a common random walk process which may lead to spurious regression results. To address this problem, we take advantage of the Johansen procedure that allows estimating the system of cointegrated relationships, by making a stationary series of their linear combination, and thus generate a forecast of their behavior towards the long run equilibrium. Additionally, the results of the Jarque-Bera test are reported in Table 6 and confirm the presence of normally distributed standard errors in the estimated model.

Table 5

Johansen tests for cointegration (sample: 1973-2014; number of obs: 42; lags: 3)

\begin{tabular}{c|c|c|c|c|c}
\hline $\begin{array}{c}\text { Maximum } \\
\text { rank }\end{array}$ & Parms & LL & Eigenvalue & $\begin{array}{c}\text { Trace } \\
\text { statistic }\end{array}$ & $\begin{array}{c}\mathbf{5} \% \\
\text { critical value }\end{array}$ \\
\hline $\mathbf{0}$ & 78 & 548.37364 &. & 121.6338 & 94.15 \\
$\mathbf{1}$ & 89 & 572.38588 & 0.68128 & 73.6093 & 68.52 \\
$\mathbf{2}$ & 98 & 587.97192 & 0.52393 & $42.4373^{*}$ & 47.21 \\
$\mathbf{3}$ & 105 & 596.01644 & 0.31824 & 26.3482 & 29.68 \\
$\mathbf{4}$ & 110 & 603.56369 & 0.30190 & 11.2537 & 15.41 \\
$\mathbf{5}$ & 113 & 608.86951 & 0.22327 & 0.6421 & 3.76 \\
$\mathbf{6}$ & 114 & 609.19055 & 0.01517 & & \\
\hline
\end{tabular}


Table 6

The Jarque-Bera test

\begin{tabular}{c|c|c|c}
\hline Equation & chi2 & df & Prob > chi2 \\
\hline D_c & 0.276 & 2 & 0.87096 \\
D_y & 1.592 & 2 & 0.61406 \\
D_y ${ }^{2}$ & 1.425 & 2 & 0.49045 \\
D_e & 0.368 & 2 & 0.83181 \\
D_a & 0.955 & 2 & 0.62022 \\
D_f & 0.382 & 2 & 0.82614 \\
All & 3.266 & 12 & 0.91940 \\
\hline
\end{tabular}

Hence, we are now in the position to study the possibility of short and long run relationships among the variables in model (2), and to infer their co-joint movements, along with their speed of convergence towards equilibrium, by estimating the two found cointegrating relationships

$$
\begin{aligned}
& c_{t}=\hat{\gamma}_{1}+\hat{\delta}_{1,2} y_{t}+\hat{\delta}_{1,3} a_{t}+\hat{\delta}_{1,4} e_{t}+\hat{\delta}_{1,5} f_{t}+\hat{u}_{t} \\
& y_{t}=\hat{\gamma}_{2}+\hat{\delta}_{2,1} c_{t}+\hat{\delta}_{2,3} a_{t}+\hat{\delta}_{2,4} e_{t}+\hat{\delta}_{2,5} f_{t}+\hat{u}_{t}
\end{aligned}
$$

which are to be used in the error correction estimation.

\subsection{Estimation of the long run and short-run coefficients}

Table 7 presents the long-term coefficients resulting from the VECM estimates along with the error correction term (ECT) and the short-run coefficients. Table 7 also reports the results of the LM-test for autocorrelation, showing that the null of no autocorrelation cannot be rejected. For the scope of our analysis, we shall concentrate on the possible causality channel linking pollution to economic growth and tourism arrivals. Granger causality is checked among our series to test if the information contained in the past values of selected variable may help to predict the evolution of another variable. In presence of cointegrated series, Granger causality test allows us to predict their long run relationship, meaning that the policymaker may calibrate its policy action according to the speed of convergence of the series towards the mutual long run equilibrium.

Table 7

\begin{tabular}{|c|}
\hline (I) Cointegrating vectors and long run estimates \\
\hline (I. a) $c=\frac{-.007 y}{(0.000)}+\frac{-.012 y^{2}}{(0.694)}+\frac{.301 e}{(0.000)}+\frac{.415 a}{(0.000)}+\frac{.199 f}{(0.000)}$ \\
\hline (I. b) $y=\frac{.003 e}{(0.018)}+\frac{.004 a}{(0.003)}+\begin{array}{c}.001 f \\
(0.049)\end{array}$ \\
\hline Adj. $R^{2}=0.785, \mathrm{LM}=28.0176[0.82657]$ \\
\hline
\end{tabular}

Long run and short-run estimates and causality results

\begin{tabular}{c|c|c|c|c|c}
\hline \multicolumn{7}{c}{ (II) Short-run estimates and causality network } \\
\hline $\begin{array}{c}\text { Dependent } \\
\text { variable }\end{array}$ & \multicolumn{5}{|c}{$\begin{array}{c}\text { Independent } \\
\text { variables }\end{array}$} \\
\hline & $\Delta c$ & $\Delta y$ & $\Delta a$ & $E C T_{1, t-1}$ & $E C T_{2, t-1}$ \\
\hline$\Delta c$ & - & $-50.15^{*}[0.078]$ & $2.78^{* * *}[0.000]$ & $-.51^{* * *}[0.006]$ & $.98^{* * *}[0.006]$ \\
\hline$\Delta y$ & $n s$ & - & $3.44^{* * *}[0.001]$ & $-1.44[0.229]$ & $2.78^{* *}[0.029]$ \\
\hline$\Delta a$ & $9.98[0.407]$ & $31.57^{* * *}[0.000]$ & - & $1.96[0.403]$ & $-3.79^{* * *}[0.003]$ \\
\hline
\end{tabular}

Notes: t-statistics are reported in parentheses and probability values into brackets. ${ }^{*}, * * * * *$ indicate significance at $10 \%, 5 \%$, and $1 \%$, respectively; $n$ s stands for no significance of the estimates. Subscripts are avoided in all variables. 
Therefore, focusing on the first cointegrating vector (I.a), as it emerges from Table 7 , since the $E C T_{1, t-1}$ is negative and significant (as expected), it can be concluded that, in the long run, $c$ converges with $y$ and $a$, when its short-term value is adjusted.

According to the estimated coefficients, there exists a long run negative relationship linking polluting emissions to real GDP, which might push in favor of the statements of the EKC framework. That is to say that Japan has already passed the turning point and that we might expect a continuous trend to reduce $\mathrm{CO}_{2}$ emissions as we foster economic growth. The Wald test has produced no evidence of a possible structural break due to the 2011 accident in the Fukushima nuclear plant. The test provided a $\chi^{2}$ statistic of 10.2613 (0.1141), with p-values reported in brackets, which cannot reject the null hypothesis of no structural break. We can therefore conclude that this event did not break the emerging causality relationship between energy use and GDP. This can be explained by a possible substitution effect among energy sources. That is to say, the reduction of energy produced by the dismissed nuclear plant has been easily compensated by an augment of energy generated by the import of fossil fuels, thus leaving the total level of energy used in production basically unaffected.

The non-significance of the $y^{2}$ coefficient confirms this conclusion. At the same time, the positive and significant elasticity of tourism arrivals also suggests that a $1 \%$ change in the tourism flows visiting Japan is associated to a $0.415 \%$ variation in polluting emissions in the same direction, which is stronger than the negative relationship between $\mathrm{CO}_{2}$ pollution and economic growth. The positive relationship between tourism arrivals and pollution raises the concern on the possibility that tourism development, by increasing pollution loads, can drive the Japanese economy towards a non-sustainable pattern of development. In other words, the inverted U-shaped long run relationship found between $\mathrm{CO}_{2}$ and GDP can be easily undermined by introducing another explanatory variable, such as tourism arrivals, that are positively linked to polluting emissions.

Other interesting results in Table 7 are the positive elasticities estimated for energy use and the use of fossil fuels. This means that a rise in energy use or an increase in the amount of fossil fuels in the production process positively affects the generated $\mathrm{CO}_{2}$ emissions in the atmosphere.

Moving to the second cointegrating equation (I.b), we can observe a production-function-type relationship. The long run relationship estimated strengthens our result, since - as expected - a positive link is found between tourist arrivals and GDP. A 100\% increase in variable $a$ is associated to a rise in national income by the $0.4 \%$. It is therefore straightforward to conclude that looking at the GDP as the sole driver to achieve the long run reduction of polluting emissions is not enough, because tourism arrivals, by allowing for economic growth, can potentially contribute to reduce $\mathrm{CO}_{2}$ emissions. Therefore, the net effect of tourism development on $\mathrm{CO}_{2}$ emissions seems to depend on the composition of two opposite channels: the more tourism drives growth, the less its net impact on environmental degradation.

In this situation, it would be a wrong statement to suggest that no policy action be needed as the pollution problem will be solved by solely leaving the country grow itself. Instead, pushing up the program of increasing the number of tourists visiting the country, to expand the level of economic growth, would eventually undermine the quality of the environment.

To turn these considerations into policy implications, it is, however, necessary to determine the directions of the causality network across all variables of the model, derive the associated short-run determinants and, finally, show the support to our underlying hypotheses. The results are shown in the second part of Table 7. First, we observe that the short-term coefficients of $y$ and $a$ are a further proof of their impact on lowering $c$. In particular, as shown in Table 7, the Granger test shows that a short-run causality link exists running: $i$ ) from $a$ to $y$, with a positive sign (3.44), as expected from the TLGH; ii) from $a$ to $c$, with a positive sign (2.78), as expected from the TLPH; iii) from $y$ to $c$, with the expected negative sign (-50.15), as expected for the EKC hypothesis, when the economy evolves on the decreasing arm of the inverted-U pattern linking pollution and 
GDP growth. The reversed positive causality running from $y$ to $a$ (31.57), is not new in the literature, and simply confirms that in high-developed countries, such as Japan in our context, higher income levels act as a catch-up for tourists, because of the expected higher quality levels of services provided in the hospitality sector.

As for the long run, we notice that causality runs bi-directionally between $a$ and $y$, and unidirectionally from $a$ to $c$ and from $y$ to $c$. These findings need particular attention. All in all, they suggest that an exceedingly conservative environmental policy, which may, for example, be financed by taxing tourists, might reduce pollution, but, at the same time, it may also lower the future level of economic growth. On the other hand, causality relationships also suggest that policies that favor an increase in tourism flows also enhance economic growth, but, at the same time, they are also expected to negatively impact on the quality of the environment by causing an increase in the level of pollution. Finally, and interestingly, the reversed tourism-led growth causality running from GDP to tourism, simply means that the higher the growth level of the country, the more its ability to capture in the shares of international tourism, due to the expected higher quality levels of services supplied in the hospitality sector.

To summarize, as represented in the causality triangle shown in Figure 2, we find that short-run and long run causality follow the same pattern.

Figure 2

Causality links and supported hypotheses

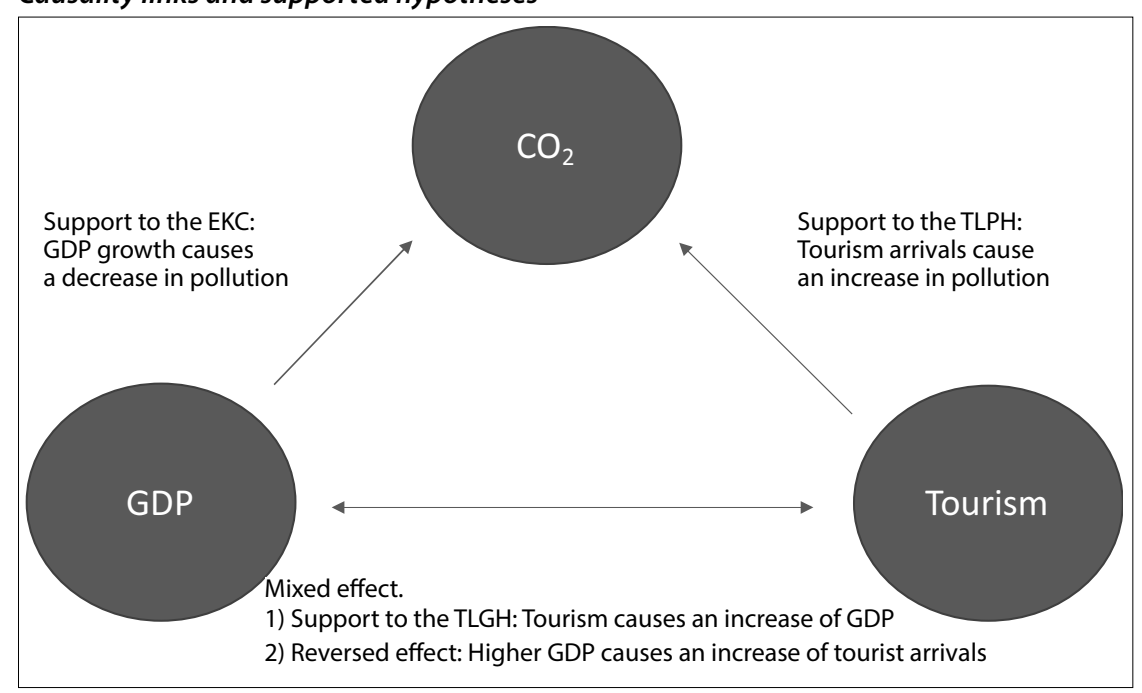

In this situation, a trade-off emerges between a policy action devoted to increasing the number of tourist arrivals, which drives economic growth, and consequently increases polluting emissions, and - on the contrary - severe policies to tightening environmental protection by lowering mass tourism arrivals, which depress economic growth. All in all, Japan might decide between increasing the number of tourists at the expense of the environment or renouncing to an increase in economic growth but moving to a more sustainable environment. The forecast scenario produced by our estimates is presented in Figure 3, where an evolutionary behavior up to the next two decades is shown for the three variables of interest. As we may observe, $\mathrm{CO}_{2}$ is expected to slightly decrease in the next years, while both GDP and tourism arrivals are projected to follow an upward trend. The full picture may lead us to the conclusion that investing in tourism activities to attract an increasing number of tourists will definitely benefit the Japanese economy in terms of a rise in GDP, and more importantly, that this will not be detrimental for the sustainable equilibrium of the economy, because the engine driven by the EKC scenario is at work. Hence, if the structure of preferences of the Japanese society will continue to call for environmental protection, and the growth of the country is not occurring at 
the expenses of the environmental quality (i.e., new investment activities and supplied tourism services are in line with the international protocols aimed at achieving resource conservation), then the path for a long run sustainable development will be granted for the future generation.

\section{Figure 3}

Forecast scenario

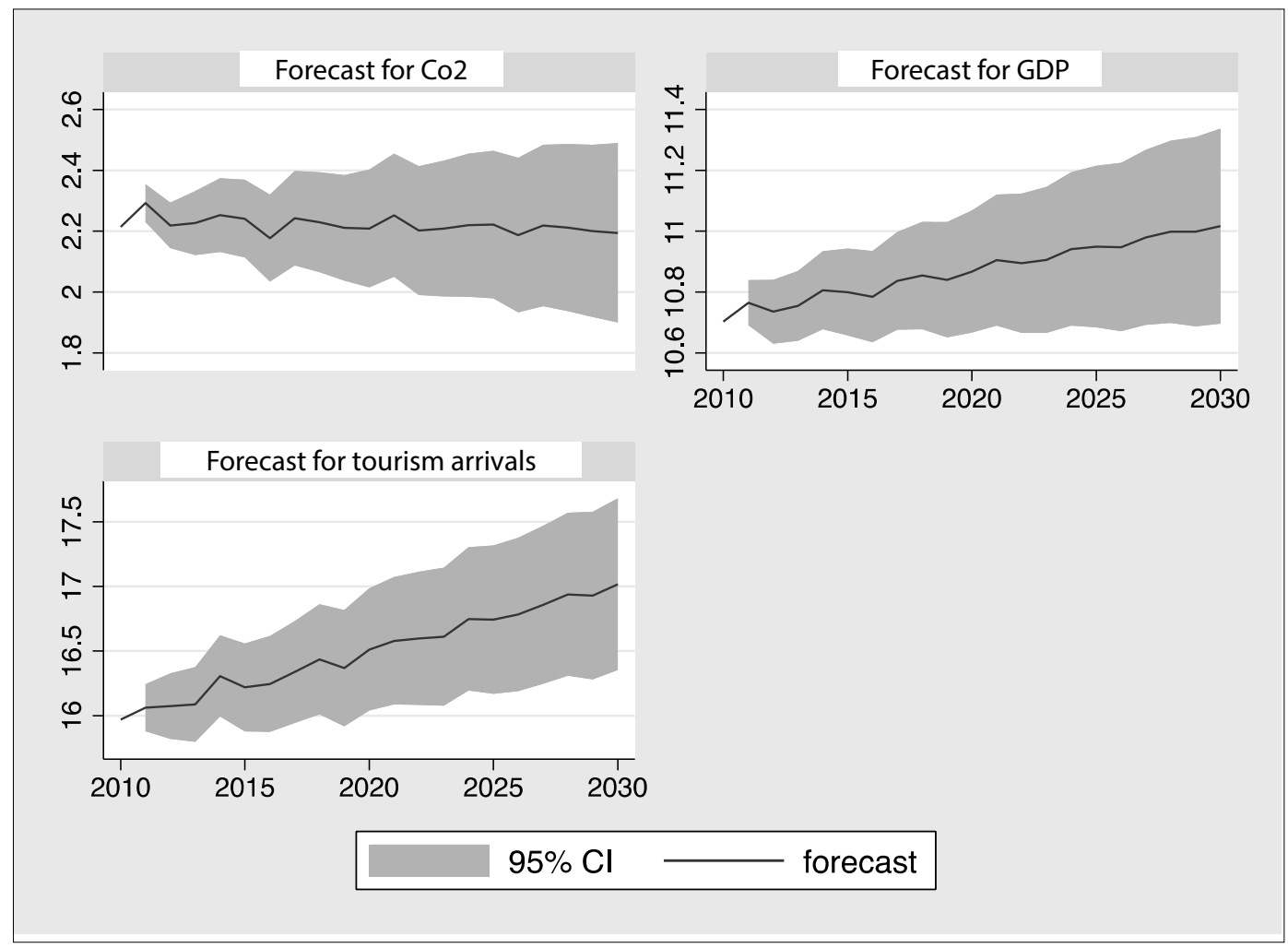

\section{Conclusions and policy implications}

This study provided an in-depth investigation of the role of tourism on $\mathrm{CO}_{2}$ pollution in Japan, a major tourist destination of the last decade. The main scope was to estimate the long-term equilibrium relationship and the direction of causality between polluting emissions, output growth, and tourism. At this scope, we have defined a VECM with the principal aim of studying the short-run and long run causality directions running between the variables that compose our model.

Results have shown that the time series of the variables in our model contain a unit root and become stationary after the first difference. Johansen cointegration test revealed the presence of two cointegrating vectors; the first one simulates the standard EKC model, whereas the second reproduces a production-function-type relationship. The two cointegrating vectors jointly validated the presence of a long run positive relationship linking tourism arrivals with both $\mathrm{CO}_{2}$ emissions and national income, and of a decreasing relationship between our measure of environmental degradation and national income. Long run and short-run parameters revealed that a bi-directional causal relationship characterizes tourism and income, whereas causality runs unidirectionally from tourism to pollution and from income to pollution.

The results of this study support the recent strategic blueprint subscribed by Japan policymakers, due to their commitment to the sustainable growth pattern imposed by the UN Climate Change Agreement signed in 
Paris in 2015 at the COP 21 to reduce greenhouse gas emissions by $26 \%$ within in the next two decades. The scope is to encourage the adoption of best practices among all players in the tourism industry and raise awareness about environmental preservation. The decision of the Japanese Tourism Agency to join the Global Sustainable Tourism Council principles as part of its public policy, is a further signal of the ambitious plan to upgrade the tourism industries to fit the tourists' needs in a sustainable way. Among these initiatives, particular relevance is given to becoming a more energy-efficient consumer by lowering the dependence on nuclear power generation, boost the use of hydrogen power, and let renewable energy become the major power plants source. This emphasizes the importance of pushing towards environmental conservation policies and move to a decarbonized economy by the end of 2050, but not at the cost of pushing tourists to other competing Asian destinations with less environmental constraints, which would negatively impact on Japan's national income. Further research is thus required to assess the validity and effectiveness of this sustainable action.

It should be noted that Japan has a minimal supply of natural resources, and the country depends mostly on imported fossil fuels, so that joint with the fact that public concern over the safety of nuclear plants following the 2011 Fukushima accident is still high, the country seems to be hooked on coal use. The percentage of coal in the electricity mix has, in fact, actually tripled from $10 \%$ in the early 1990 s to $31 \%$ in 2015 . It is then not surprising that fossil fuels still dominate the energy sector. Moreover, Japan has been very slow in enhancing domestic energy efficiency, since homes in Japan are designed to be earthquake-proof-safe and thus are built with the humid summer weather in mind, this implying that all buildings have thin walls that provide minimal insulation, so resulting in the overuse of air conditioning units both in the summer and in the winter.

In this scenario, Japan's contribution to meeting the targets of the Paris goals seems quite ambitious and almost unrealistic. Nevertheless, these developments can be achieved with the commitment of national families, tourism stakeholders, and international visitors if they fully grasp that the climate change problem is not a remote or future threat. Still, our study has confirmed that when policy action and managerial plans are made in favor of a sustainable use of tourist destinations, then tourism becomes a secure driver for economic growth, by improving the wealth of citizens with no harm for environmental safety. In this view, we can discuss hereafter few examples that present the latest tourism-related measures being adopted to turn Japan into a sustainable tourism destination.

The first strategy regards the increasing pressure to move tourism flows off the standard Tokyo-Kyoto-Osaka triangle in favor of trips to visit the rural communities, by using the efficient and high-speed public railtransport network, with the scope of increasing the number of nights spent in the traditional family-run inns (Giampiccoli et al., 2020). This will simultaneously act as a benefit to the wealth of rural communities and reduce the pressure on the need for new hotels and hospitality services, as the local accommodations might be used to the scope (Wolf-Watz, 2014; Falak et al., 2016). Just to give a hint of the path induced by this change, let us only think to the estimated 20 billion chopsticks that are thrown away a year in the city hotels and traditional restaurants, and how the carbon footprint of the tourism sector might be reduced if home facilities for domestic personal consumption were used instead. Additionally, visits in the surroundings of such small rural areas, with their fisheries and wineries, enables to commute the use of standard car transport by the use of on foot or cycle hiking with a lowering or no energy source needed at all.

As a signal of an increasing demand for sustainable practices in the Japanese tourism sector, of particular interest is the increasing number of hotels asking for a "green certification". For example, given the quality of safe public water, it is not odd to find hotels that promote the use of refillable water bottles, thus giving a fundamental help in the management of freshwater conservation and the reduction of plastic waste.

Finally, it is noteworthy to consider that the appalling impact of the recent coronavirus pandemic, and the need of increasing social distancing and lowering flight movements, might paradoxically increase the demand for visits in such less crowded rural places, which in turn will result in a support for a more diversified and 
sustainable tourism. This new scenario puts Japan at a pivotal moment of its tourism history, since the wayout to the pandemic, and the strategies adopted for the incumbent take-off expected by the Olympic games, will give a crucial signal on the effective way the country is challenging the issue of attracting international tourism flows in a sustainable way.

\section{References}

Adamou, A., \& Clerides, S. (2010). Prospects and limits of tourism led growth: The international evidence. Review of Economic Analysis, 3, 287-303.

Aliyev, K., \& Ahmadova, N. (2020). Testing tourism-led economic growth and economic-driven tourism growth hypotheses: The case of Georgia. Tourism: An International Interdisciplinary Journal, 68(1), 43-57.

Andonian, A., Kuwabara, T., Yamakawa, N., \& Ishida, R. (2016). The future of Japan's tourism: Path for sustainable growth towards 2020. McKinsey Japan and Travel, Transport and Logistics Practice. McKinsey \& Company.

Apergis, N., \& Payne, J. (2009). Energy consumption and economic growth: Evidence from the Commonwealth of Independent States. Energy Economics, 31, 641-647.

Arbulù, I., Lozano, J., \& Rey-Maquieira, J. (2015). Tourism and solid waste generation in Europe: A panel data assessment of the environmental Kuznets curve. Waste Management, 46, 628-636.

Balaguer, J., \& Cantavella-Jorda, M. (2002). Tourism as a long run economic growth factor: The Spanish case. Applied Economics, 34, 877-884.

Bella, G. (2018). Estimating the tourism induced environmental Kuznets curve in France. Journal of Sustainable Tourism, $26,2043-2052$.

Brida, J.G., Lanzilotta, B., Pereyra, J.S., \& Pizzolon, F. (2015). A nonlinear approach to the tourism led growth hypothesis: The case of MERCOSUR. Current Issues in Tourism, 18, 647-666.

Castro Nuño, M., Molina Toucedo, J.A., \& Pablo Romero, M.P. (2013). Tourism and GDP: A meta-analysis of panel data studies. Journal of Travel Research, 52, 745-758.

Copeland, B.R., \& Taylor, M.S. (2004). Trade, growth and the environment. Journal of Economic Literature, 42, 7-71.

De Vita, G., Katircioglu, S., Altinay, L., Fethi, S., \& Mercan, M. (2015). Revisiting the environmental Kuznets curve hypothesis in a tourism development context. Environmental Science and Pollution Research, 22, 16652-16663.

Dinda, S. (2004). Environmental Kuznets curve hypothesis: A survey. Ecological Economics, 49, 431-455.

Falak, S., Chiun, L.M., \& Wee A.Y. (2016). Sustainable rural tourism: An indigenous community perspective on positioning rural tourism. Tourism: An International Interdisciplinary Journal, 64(3), 311-327.

Giampiccoli, A., Mtapuri, O., \& Dłużewska, A. (2020). Investigating the intersection between sustainable tourism and community-based tourism. Tourism: An International Interdisciplinary Journal, 68(4), 415-433.

Gössling, S. (2000). Sustainable tourism development in developing countries: Some aspects of energy use. Journal of Sustainable Tourism, 8, 410-425.

Gössling, S., Peeters, P., Ceron, J. P., Dubois, G., Patterson, T., \& Richardson, R.B. (2005). The ecoefficiency of tourism. Ecological Economics, 54, 417-434.

Grossman, G.M., \& Krueger, A.B. (1995). Economic growth and the environment. Quarterly Journal of Economics, $110,352-377$.

Gujarati, D.N. (2003). Basic econometrics. McGraw Hill.

Gwenhure, Y., \& Odhiambo, N.M. (2017). Tourism and economic growth: A review of international literature. Tourism: An International Interdisciplinary Journal, 65(1), 33-44.

Henriques, T., \& Borowiecki, K.J. (2017). The drivers of long run CO2 emissions in Europe, North America and Japan since 1800. Energy Policy, 101, 537-549. 
Johansen, S. (1988). Statistical analysis of cointegration vectors. Journal of Economic Dynamics and Control, 12, $231-254$.

Johansen, S. (1991). Estimation and hypothesis testing of cointegration vectors in gaussian vector autoregressive models. Econometrica, 59, 1551-1580.

Johansen, S. (1995). Likelihood-based Inference in cointegrated vector autoregressive models. Oxford University Press.

Katircioglu, S. (2009). Tourism, trade and growth: The case of Cyprus. Applied Economics, 41, 2741-2750.

Katircioglu, S. (2010). Research note: Testing the tourism-led growth hypothesis for Singapore - An empirical investigation from bounds test to cointegration and Granger causality tests. Tourism Economics, 16, 1095-1101.

Katircioglu, S.T. (2014a). Testing the tourism-induced EKC hypothesis: The case of Singapore. Economic Modelling, 41, 383-391.

Katircioglu, S.T. (2014b). International tourism, energy consumption, and environmental pollution: The case of Turkey. Renewable and Sustainable Energy Reviews, 36, 180-187.

Katircioglu, S.T., Feridun, M., \& Kilinc, C. (2014). Estimating tourism-induced energy consumption and CO2 emissions: The case of Cyprus. Renewable and Sustainable Energy Reviews, 29, 634-640.

Lean, H.H., \& Smyth, R. (2010). CO2 emissions, electricity consumption and output in ASEAN. Applied Energy, 87, 1858-1864.

Ozturk, I., Al-Mulali, U., \& Saboori, B. (2015). Investigating the environmental Kuznets curve hypothesis: The role of tourism and ecological footprint. Environmental Science and Pollution Research, 23, 1916-1928.

Paramati, S.R., Alam, M.S., \& Chen, C.F. (2017). The effects of tourism on economic growth and CO2 emissions: A comparison between developed and developing economies. Journal of Travel Research, 56, 712-724.

Po, W., \& Huang, B. (2008). Tourism development and economic growth - A nonlinear approach. Physica A, 387, 5535-5542.

Stern, D.I. (2004). The rise and fall of the environmental Kuznets curve. World Development, 32, 1419-1439.

Wolf-Watz, D. (2014). Traveling for nature? On the paradox of environmental awareness and travel for nature experiences. Tourism: An International Interdisciplinary Journal, 62(1), 5-18.

World Bank. (2016). World development indicators. https://datacatalog.worldbank.org/dataset/world-development-indicators

World Tourism Organization. (2008). Climate change and tourism.

Zaman, K., Shahbaz, M., Loganathan, N., \& Raza, S.A. (2016). Tourism development, energy consumption and environmental Kuznets curve: Trivariate analysis in the panel of developed and developing countries. Tourism Management, 54, 275-283.

Received: September 17, 2020

Revised: February 04, 2021

Revised: March 09, 2021

Accepted: March 10, 2021

Refereed Anonymously 